\title{
CASC8 IncRNA Promotes the Proliferation of Retinoblastoma Cells Through Downregulating miR34a Methylation
}

This article was published in the following Dove Press journal: Cancer Management and Research

\author{
Bo Yang* \\ Baoyu Gu* \\ Jing Zhang \\ Long $\mathrm{Xu}$ \\ Yong Sun
}

Department of Ophthalmology, Shenzhen Hospital of Integrated Chinese and Western Medicine, Shenzhen 5I8I0I, Guangdong Province, People's Republic of China

*These authors contributed equally to this work
Correspondence: Yong Sun

Department of Ophthalmology, Shenzhen Hospital of Integrated Chinese and Western Medicine, 3 Shajing Street, Bao'an District, Shenzhen 51810I, Guangdong Province, People's Republic of China

Tel +86 755-2772-224l

Emailwk97I0@I63.com
Background: $C A S C 8$ lncRNA has been proven to be oncogenic in a variety of cancers, but its role in other types of cancer remains unclear. This study was to investigate the role of CASC8 in retinoblastoma $(\mathrm{Rb})$.

Methods: RT-qPCR was performed to determine the expression of $C A S C 8$ and miR34a in paired $\mathrm{Rb}$ and nontumor tissue. Overexpression of CASC8 and miR34a in Rb cells was achieved to evaluate the interaction between them. Methylation-specific PCR was used to analyze the effect of CASC8 overexpression on MIR34A gene methylation. CCK 8 assays were used to analyze cell proliferation.

Results: The results showed that $C A S C 8$ expression was upregulated and miR34a expression downregulated in $\mathrm{Rb}$ tissue. Moreover, miR34a expression was negatively correlated with the of CASC8 expression in $\mathrm{Rb}$ tissue. Overexpression of CASC8 decreased expression of miR34a and increased methylation of MIR34A in Rb cells. In addition, overexpression of CASC8 reduced the inhibitory effects of miR34a on $\mathrm{Rb}$-cell proliferation.

Conclusion: $C A S C 8$ may promote $\mathrm{Rb}$ cell proliferation by downregulating miR34a methylation.

Keywords: retinoblastoma, $C A S C 8$, miR34a, methylation, proliferation

\section{Introduction}

Retinoblastoma $(\mathrm{Rb})$ is a rare malignant tumor that originates from the photosensitive tissue of the eye, known as the retina. ${ }^{1} \mathrm{Rb}$ is caused mainly by genetic mutation in retinal nerve cells. Cells with certain mutations will grow uncontrollably, leading to the formation of tumors. ${ }^{2} \mathrm{Rb}$ affects mainly patients $<5$ years old. ${ }^{3}$ With proper treatment, $95 \%$ of $\mathrm{Rb}$ patients can be cured, and both eyes can be saved in $70 \%-80 \%$ cases. ${ }^{4,5}$ However, Rb in some cases can also spread to other parts of the body, such as the spine and brain, leading to poor prognosis. ${ }^{6}$ Therefore, novel therapeutic approaches are needed to further improve the survival of $\mathrm{Rb}$ patients.

Molecular factors play crucial roles in the pathogenesis of $\mathrm{Rb}^{7,8}$ Functional

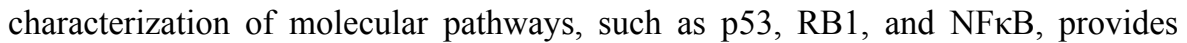
novel insights to the development of novel anticancer therapies, such as targeted therapy. ${ }^{9,10}$ It has been well established that ncRNAs, such as IncRNAs), andmiRNAs are not involved in protein synthesis, but regulate the expression of cancer-related genes to suppress or promote cancer development. ${ }^{11}$ Therefore, ncRNAs are potential targets for targeted cancer therapy. ${ }^{12}$ However, the function of most ncRNAs is barely known. IncRNA CASC8 has been proven to be 
significantly correlated with several types of cancer, such as lung cancer, ${ }^{13}$ while its involvement in $\mathrm{Rb}$ is unknown. Our preliminary RNA-seq analysis revealed altered expression of $C A S C 8$ in $\mathrm{Rb}$, and expression of $C A S C 8$ in $\mathrm{Rb}$ was negatively correlated with miR34a (data not shown), which is a well-established tumor-suppressive miRNA. ${ }^{14}$ This study was thus carried out to analyze interactions between $C A S C 8$ and miR34a in $\mathrm{Rb}$.

\section{Methods}

\section{$\mathrm{Rb}$ Patients}

The Ethics Committee of Shenzhen Hospital of Integrated Chinese and Western Medicine approved this study. A total of $62 \mathrm{Rb}$ patients ( 39 males and 23 females, 9 months to 3 years, 4 months, $2.0 \pm 0.4$ years) were enrolled at this hospital between March 2016 and January 2019. All patients were newly diagnosed $\mathrm{Rb}$ patients. No recurrent $\mathrm{Rb}$ patients were enrolled. Patients with a family history of malignancy were excluded. Before this study, no therapy had been performed on these patients. The International Classification for Intraocular Retinoblastoma was used to stage the $62 \mathrm{Rb}$ patients. Based on these criteria, patients were divided into group A $(n=11), B(n=12), C(n=10)$, $\mathrm{D}(\mathrm{n}=15)$, and $\mathrm{E}(\mathrm{n}=14)$. In addition, patients included 28 cases with low-grade $\mathrm{Rb}$ and 34 high-grade $\mathrm{Rb}$. All patients provided signed informed consent.

\section{Specimen Collection and Rb Cells}

During histopathological biopsy for the diagnosis of $R b$, paired $\mathrm{Rb}$ and nontumor tissue samples were collected from each patient. A liquid-nitrogen tank was used to store all fresh tissue samples before subsequent experiments. Y79 and C33A (ATCC) human Rb cell lines were used. Cells were cultivated in a $5 \% \mathrm{CO}_{2}$ and $95 \%$ humidity incubator at $37^{\circ} \mathrm{C}$. The cell-culture medium was composed of RPMI 1640 (80\%) and FBS (20\%).

\section{Cell Transfection}

A CASC8-expression vector was constructed using a pcDNA3.1 vector (Invitrogen) as a backbone. Vector construction was provided by Invitrogen. Mimics of miR34a and negative control (NC) miRNA were from Invitrogen. Y79 and C33A cells were cotransfected with $40 \mathrm{nM}$ miRNA mimic or $10 \mathrm{nM}$ vector using Lipofectamine 2000 (Sangon). Control cells were untransfected. NC cells were miRNA- or empty vector-transfected cells. The following experiments were carried out at 48 hours after all transfections.

\section{RNA Preparations}

A Trizol Plus RNA-purification kit (Thermo Fisher Scientific) was used to extract total RNA from both paired nontumor and $\mathrm{Rb}$ tissue samples, as well as Y79 and C33A cell lines. Genomic DNA removal was performed using DNase I (Invitrogen) at $37^{\circ} \mathrm{C}$ for 2 hours. RNA integrity was checked using a urea-PAGE gel (6\%). Only RNA samples of satisfactory quality were subjected to the following experiments.

\section{RT-qPCR}

An SSRT III reverse transcription (RT) system (Thermo Fisher Scientific) was used to perform RT to synthesize cDNA samples with RNA samples as a template. Samples of cDNA were used as a template to perform all qPCR using a Kapa SYBR Fast qPCR kit (Roche). The endogenous control of CASC8 was $18 \mathrm{~S}$ rRNA. To measure expression levels of mature miR34a, addition of poly(A), miRNA RT,
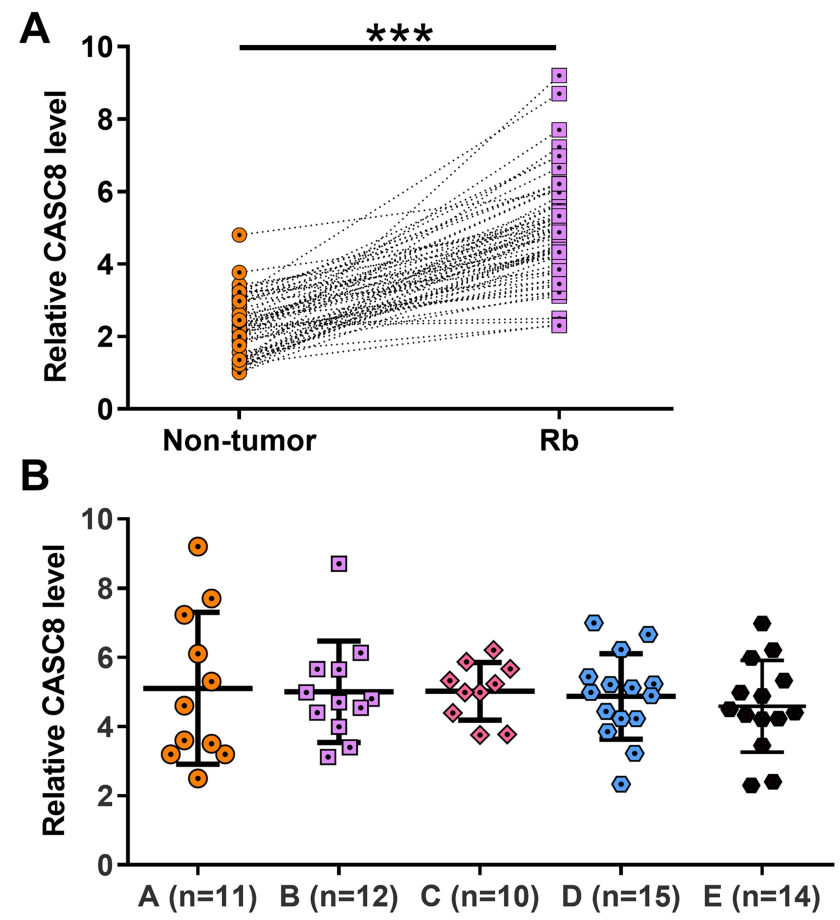

Figure I CASC8 expression was upregulated in Rb tissue. Paired $\mathrm{Rb}$ and nontumor tissue were collected from the $62 \mathrm{Rb}$ patients enrolled in this study. Tissue samples were subjected to RNA preparations and RT-qPCR used to determine the expression of CASC8 in EC. Three replicate PCRs were included in each experiment. $\mathrm{Ct}$ values of CASC8 were normalized to endogenous control I8S rRNA using the $2^{-}$ $\triangle \Delta C T$ method. The sample with the biggest $\triangle C T$ value was set to value "I". All other samples were normalized to this sample. Mean values of data are presented (A). Expression of CASC8 in Rb tissue among patients at different clinical stages (B). $* * * p<0.001$. 
and qPCRwere performed using a GeneCopoeia All-in-One miRNA qRT-PCR detection kit. The internal control of miR34a was U6. Three replicates were included in each experiment. The $2^{-\Delta \Delta C T}$ method was used to normalize gene-expression levels.

\section{Methylation-Specific PCR}

Isolation of genomic DNA from Y79 and C33A cells was performed using a Monarch genomic DNA-purification kit (NEB), with all steps performed following the manufacturer's instructions. DNA samples were converted using a Methylation-Gold kit (Zymo Research). To analyze methylation of the MIR34A gene, methylation-specific PCR and routine PCR were performed using Taq $2 \times$ master mix (NEB). PCR products were sequenced to make sure that the correct PCR products were obtained.

\section{CCK8 Assays}

Y79 and C33A cells were collected at 48 hours posttransfection. Cells were digested with $0.25 \%$ trypsin, washed with cold PBS, and counted. Cells were then cultivated in a 96-well plate at $37^{\circ} \mathrm{C}$ with 3,000 cells in $0.1 \mathrm{~mL}$ medium per well. To determine cell proliferatione, OD values at $450 \mathrm{~nm}$ were measured every 24 hours for 96 hours. At 4 hours before measurement, CCK8 solution (SigmaAldrich) was added to each well to reach $10 \%$.

\section{BrdU Assays}

After transfection, Y79 and C33A cells were transferred to a 96-well cell-culture plate $(3,000$ cells in $0.1 \mathrm{~mL}$ medium per well). Cell culture was performed for a further 48 hours, and peroxidase-coupled anti-BrdU antibody (Sigma-Aldrich) was used to incubate cells after fixation. Peroxidase substrate was then used to incubate cells for 2 hours after washing, and OD values at $450 \mathrm{~nm}$ were measured later.

\section{Statistical Analysis}

Data of three biological replicates of each experiment are expressed as means $\pm \mathrm{SD}$. Paired $t$-tests were used to compare paired tissue samples. ANOVA with Tukey's test was used to compare multiple groups. Correlations were analyzed by linear regression. $P<0.05$ was statistically significant.
A

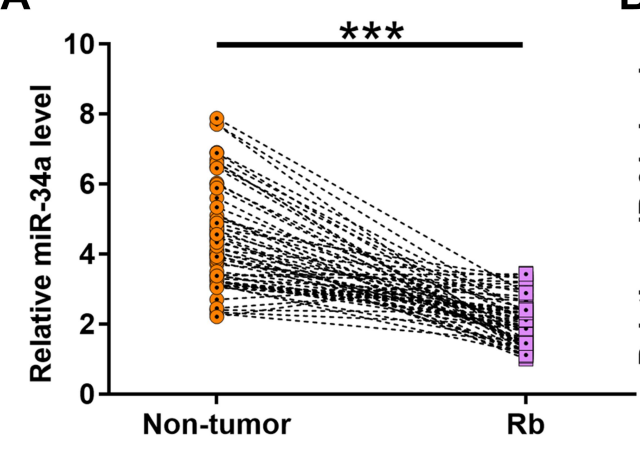

C

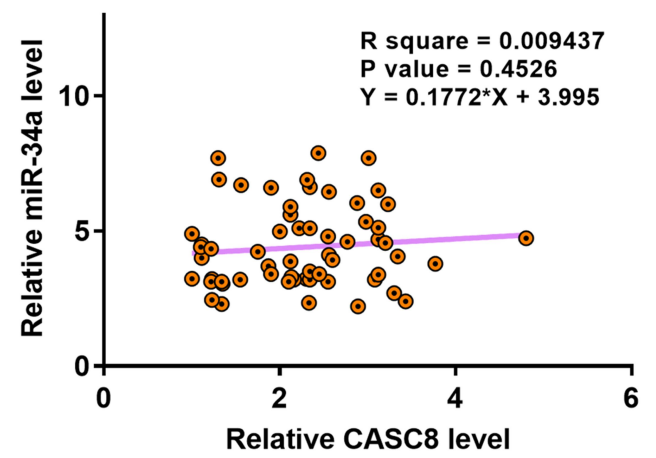

B

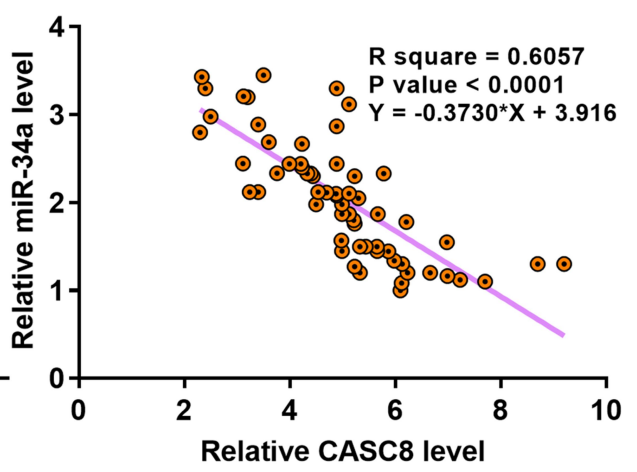

Figure 2 Expression of miR34a was downregulated in Rb and inversely correlated with CASC8 expression. Paired Rb and nontumor tissue from 62 Rb patients were also subjected to RNA preparations and RT-qPCR used to analyze differential expression of miR34a in Rb. Ct values of miR34a were normalized to the endogenous control, U6, using the $2^{-\Delta \Delta C T}$ method. The sample with the biggest $\Delta C T$ value was set to value "I". All other samples were normalized to this sample. Three replicate PCRs were included in each experiment. Mean values of data are presented $(\mathbf{A})$. ${ }^{* * *} p<0.00$ I. Linear regression was carried out to analyze correlations between expression levels of miR34a (B) and CASC8 $(\mathbf{C})$ across Rb tissue and nontumor tissue. 


\section{Results}

\section{Expression of CASC8 Upregulated in Rb} tissue

Expression of CASC8 in paired $\mathrm{Rb}$ and nontumor tissue samples was determined by RT-qPCR. Compared with non-tumor tissue, expression of $C A S C 8$ was significantly higher in $\mathrm{Rb}$ tissue (Figure $1 \mathrm{~A}, p<0.001$ ), indicating the possible involvement of $C A S C 8$ in $\mathrm{Rb}$. Expression of $C A S C 8$ in $\mathrm{Rb}$ tissue was compared among patients at different clinical stages. It was observed that CASC8 expression was not significantly different among groups A-E (Figure 1B).
miR34a Downregulated in $\mathrm{Rb}$ and Inversely Correlated with CASC8

Expression of miR34a in paired $\mathrm{Rb}$ and nontumor tissue samples from $62 \mathrm{Rb}$ patients was determined by RT-qPCR. It was observed that expression of miR34a was significantly decreased in $\mathrm{Rb}$ tissue compared with nontumor tissue (Figure 2A, $p<0.001$ ). Linear regression was carried out to analyze the correlation between the expression of miR34a and $C A S C 8$ across $\mathrm{Rb}$ tissue and nontumor tissue. It was found that the expression of miR34a and $C A S C 8$ were inversely and significantly correlated in $\mathrm{Rb}$ tissue (Figure 2B). However, the correlation between them was not significant in nontumor tissue (Figure 2C).
A

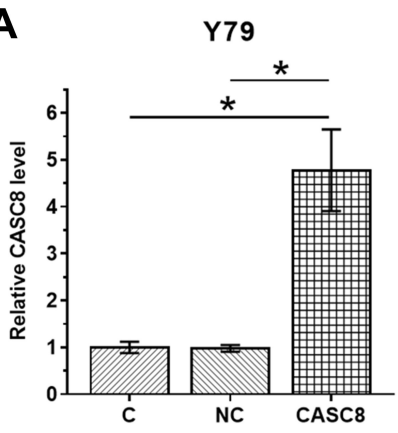

B

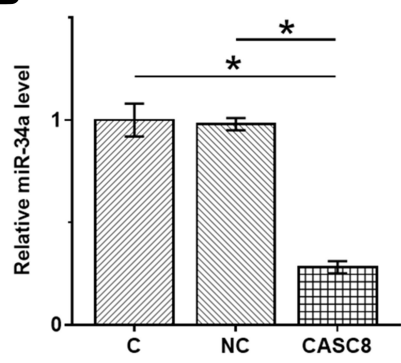

C-33A

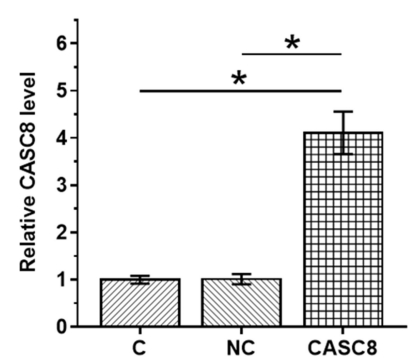

C-33A

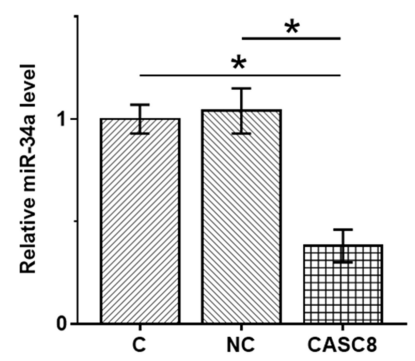

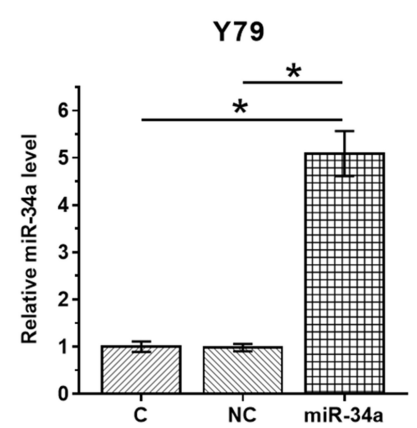

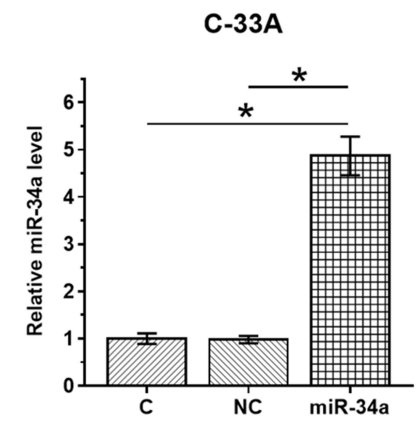

C
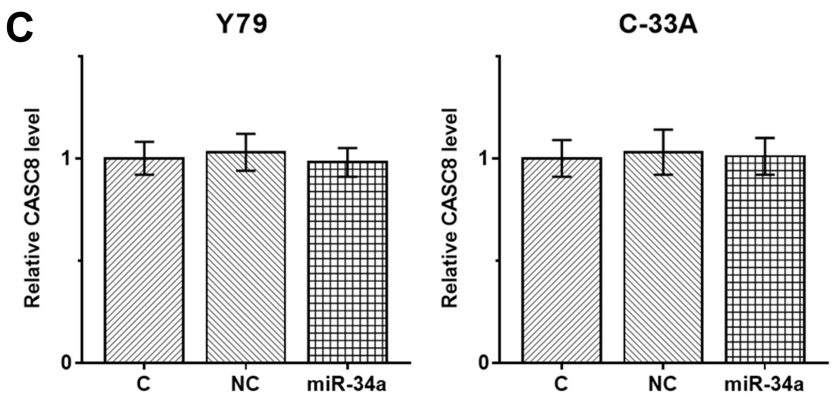

D
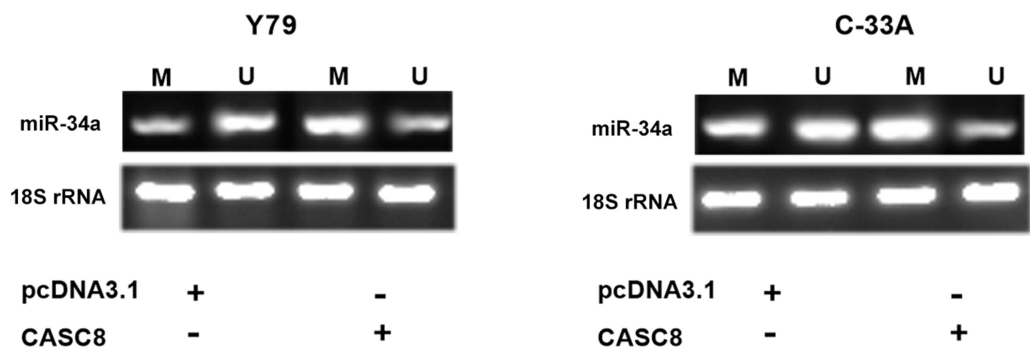

Figure 3 CASC8 overexpression downregulated miR34a in Rb cells through methylation. To analyze possible interactions between CASC8 and miR34a, a CASC8 expression vector or miR34a mimic was transfected into Y79 and C33A cells. RT-qPCR was performed at 48 hours posttransfection to confirm overexpression of CASC8 and miR34a (A). Expression of miR34a in cells with CASC8 overexpression (B) and expression of CASC8 in cells with miR34a expression (C) were also analyzed by RT-qPCR (C). Values of the control group were set to "I", and other groups were normalized to the control group. MSP was performed on cells transfected with either empty pCDNA3.I vector or cells transfected with a CASC8 -expression vector to analyze the effects of CASC8 overexpression on methylation of miR34a (D). Three independent replicates were included in each experiment, and data are expressed as means \pm SD. $* p<0.05$.

Abbreviations: M, methylation; U, unmethylaed; C, control (no transfection); NC, negative control (cells transfected with empty vector or NC miRNA). 


\section{CASC8 Overexpression Downregulated} miR34a in Rb Cells Through Methylation

To analyze possible interactions between CASC8 and miR34a, the CASC8-expression vector or miR34a mimic was transfected into Y79 and C33A cells. RT-qPCR was performed at 48 hours posttransfection to confirm overexpression of $C A S C 8$ and miR34a (Figure 3A, $p<0.05$ ). Compared with controls, downregulated miR34a was observed in cells transfected with the $C A S C 8$-expression vector (Figure $3 \mathrm{~B}, p<0.05$ ), while no significant effect on $C A S C 8$ expression was observed after miR34a-mimic transfection (Figure $3 \mathrm{C}, p>0.05$ ). Methylationspecific PCR was performed to analyze the effects of $C A S C 8$ overexpression on methylation of miR34a. Compared with cells transfected with the empty vector, cells transfected with CASC8-expression vector showed significantly increased methylation of miR34a (Figure 3D).
A

\section{Y79}

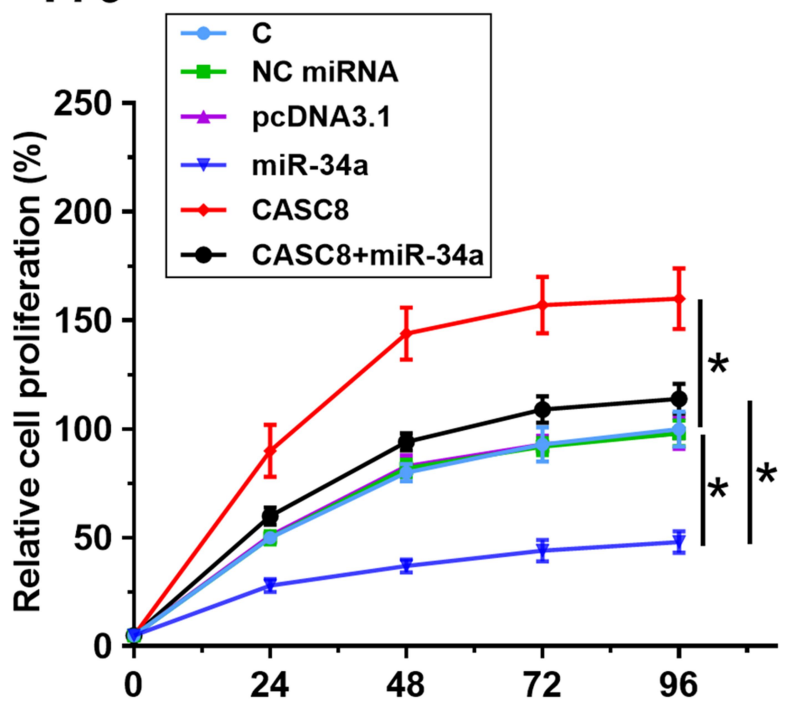

B

Time (h)

\section{CCK-8 assay}

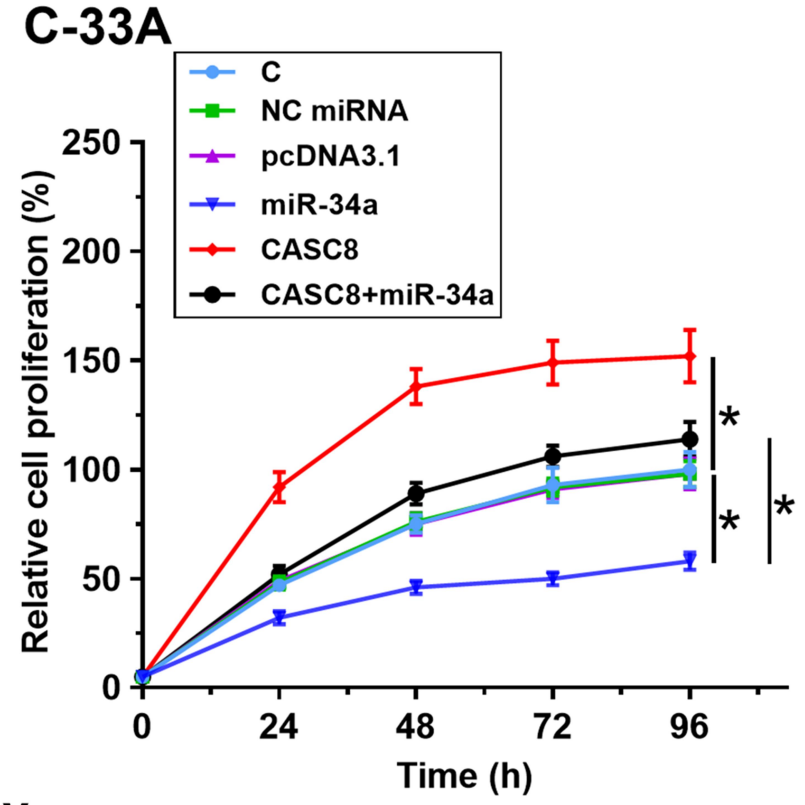

\section{Y79}

BrdU assay

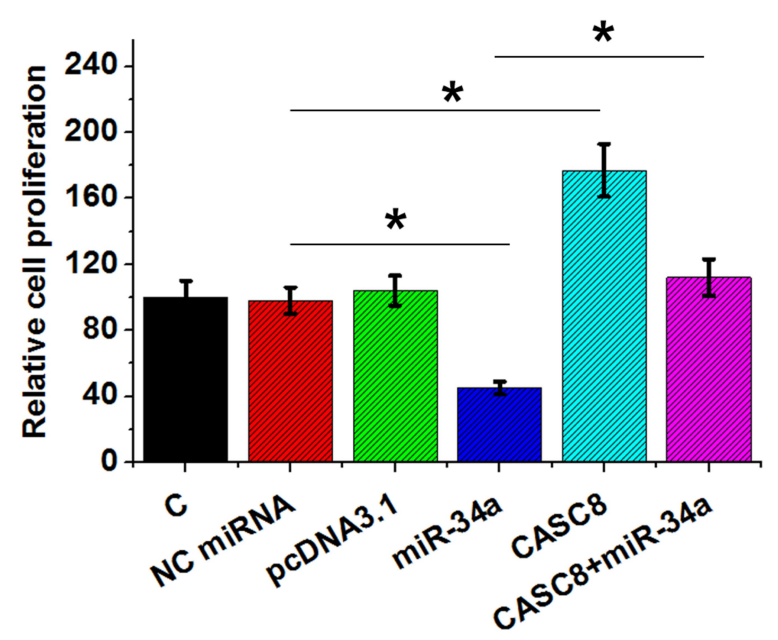

\section{C-33A}

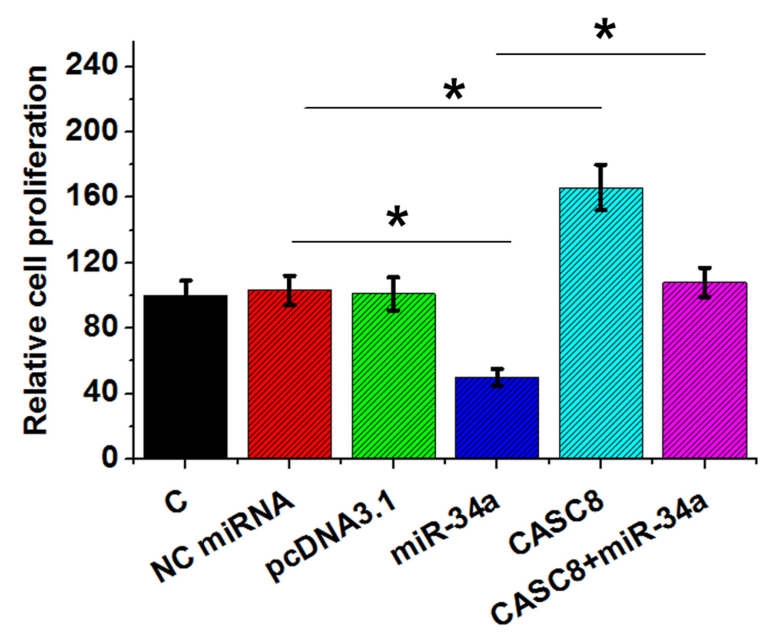

Figure 4 CASC8 overexpression promoted the proliferation of Rb cells through miR34a. Possible involvement of CASC8 in regulation of proliferation of Rb cells was analyzed by both CCK8 $(\mathbf{A})$ and BrdU assays (B). Cell proliferation was reflected by OD values measured at $450 \mathrm{~nm}$. For CCK 8 assays, measurement of OD values was performed every 24 hours until 96 hours. For BrdU assays, cells were fixed after cell culture for a further 48 hours and OD values measured later. Three independent replicates were included in each experiment, and data are expressed as means \pm SD. $* p<0.05$.

Abbreviations: C, control (no transfection); NC, negative control (cells transfected with empty vector or NC miRNA). 


\section{CASC8 Overexpression Promoted} Proliferation of Rb Cells Through miR34a

Possible involvement of CASC8 in regulation of the proliferation of $\mathrm{Rb}$ cells was analyzed by CCK8 (Figure 4A) and BrdU assays (Figure 4B). Compared with the control group, CASC overexpression significantly increased the proliferation rate of $\mathrm{Rb}$ cells, while miR34a overexpression significantly decreased the proliferation rate of $\mathrm{Rb}$ cells. In addition, CASC 8 overexpression reduced the inhibitory effects of miR34a on $\mathrm{Rb}$-cell proliferation (Figure 4, $p<0.05)$.

\section{Discussion}

In this study, we analyzed the interaction between $C A S C 8$ and miR34a in $\mathrm{Rb}$, and found that $C A S C 8$ expression was upregulated in $\mathrm{Rb}$. Moreover, CASC8 downregulated expression of miR34a by methylation of the MIR34A gene, thus promoting the proliferation of $\mathrm{Rb}$ cells.

Studies have investigated correlations between genetic polymorphisms of CASC8 and the risk of cancer. ${ }^{15}$ It has been observed that compared with the population with the rs10505477 TT genotype, those with TC or CC genotype were at significantly decreased risk of many types of cancer. ${ }^{15}$ Correlations between CASC 8 polymorphisms and risk of cancer have been reported in colorectal cancer, ${ }^{16}$ hepatocellular carcinoma, ${ }^{17}$ lung cancer, ${ }^{13}$ and acute lymphoblastic leukemia. ${ }^{18}$ However, the expression pattern and function of CASC 8 in cancer biology remains unclear. This study is the first to report on the upregulation of CASC8 in $\mathrm{Rb}$. In addition, we found that upregulation of $C A S C 8$ increased the proliferation rate of $\mathrm{Rb}$ cells. Therefore, CASC 8 may play oncogenic roles in $\mathrm{Rb}$ by promoting cancer-cell proliferation.

miR34a plays tumor-suppressive roles in many types of cancer, including $\mathrm{Rb}^{19-22}$ In cancer biology, miR34a targets multiple oncogenic genes, such as CD44 and CMET, to suppress the growth and metastasis of tumors. In $\mathrm{Rb}$, miR34a not only regulates the chemosensitivity of cancer cells to chemotherapy ${ }^{19}$ but also suppresses cancer development by inhibiting cancer-cell proliferation. ${ }^{20}$ Therefore, overexpression of miR34a is considered a promising target for the treatment of $\mathrm{Rb}$. However, based on our knowledge, the upstream regulator of miR34a in many cancers, including $\mathrm{Rb}$, is unknown. This study confirmed the inhibitory effects of miR34a on Rb-cell proliferation. miR34a is involved in cancer biology mainly through interaction with cancer- related pathways, such as MAGEA-p53 signaling. ${ }^{19}$ Our results showed that $C A S C 8$ might be an upstream inhibitor of miR34a, and could downregulate the expression of miR34a through a methylation pathway. However, the methylation factors involved in this process remain unclear.

Interestingly, we found that CASC8 and miR34a were inversely correlated in $\mathrm{Rb}$ tissue, but not nontumor tissue. Therefore, the interaction between CASC 8 and miR34a might be mediated by certain pathological factors. Future studies are needed to identify these factors.

In conclusion, the expression of $C A S C 8$ is upregulated in $\mathrm{Rb}$, and $C A S C 8$ may upregulate miR34a expression in $\mathrm{Rb}$ cells through methylation of the MIR34A gene, thus promoting the proliferation of $\mathrm{Rb}$ cells.

\section{Ethics Approval and Consent to Participate}

The Ethics Committee of Shenzhen Hospital of Integrated Chinese and Western Medicine approved this study, and informed consent was obtained from all participants. Data collected from participants were kept confidential and accessible only by the researchers.

\section{Acknowledgments}

We thank the reviewers for all constructive suggestions.

\section{Author Contributions}

All authors made substantial contributions to conception and design, acquisition of data, or analysis and interpretation of data, took part in drafting the article or revising it critically for important intellectual content, agreed to submit to the current journal, gave final approval to the version to be published, and agree to be accountable for all aspects of the work.

\section{Disclosure}

The authors declare that there are no competing interests associated with the manuscript.

\section{References}

1. Dimaras H, Kimani K, Dimba EAO, et al. Retinoblastoma. Lancet. 2012;379(9824):1436-1446. doi:10.1016/S0140-6736(11)61137-9

2. Benavente CA, Dyer MA. Genetics and epigenetics of human retinoblastoma. Annu Rev Pathol. 2015;10:547-562. doi:10.1146/ annurev-pathol-012414-040259

3. Little MP, Kleinerman RA, Stiller CA, et al. Analysis of retinoblastoma age incidence data using a fully stochastic cancer model. Int $J$ Cancer. 2012;130(3):631-640. doi:10.1002/ijc. 26039 
4. Abramson DH, Shields CL, Munier FL, et al. Treatment of retinoblastoma in 2015: agreement and disagreement. JAMA Ophthalmol. 2015;133(11):1341-1347. doi:10.1001/jamaophthalmol.2015.3108

5. Chawla B, Jain A, Azad R. Conservative treatment modalities in retinoblastoma. Indian $J$ Ophthalmol. 2013;61(9):479-485. doi:10.4103/0301-4738.119424

6. Abramson DH, Shields CL, Jabbour P, et al. Metastatic deaths in retinoblastoma patients treated with intraarterial chemotherapy (ophthalmic artery chemosurgery) worldwide. Int $J$ Retina Vitreous. 2017;3(1):40. doi:10.1186/s40942-017-0093-8

7. Kalmodia S, Parameswaran S, Ganapathy K, et al. Characterization and molecular mechanism of peptide-conjugated gold nanoparticle inhibiting p53-HDM2 interaction in retinoblastoma. Mol Ther Nucleic Acids. 2017;9:349-364. doi:10. 1016/j.omtn.2017.10.012

8. Yu C, Jing X, Bian Y. Molecular mechanism of NF- $\kappa$ B signal pathway in autophagy of retinoblastoma cell line HXO-RB44. Int J Clin Exp Med. 2019;12(12):13586-13591.

9. Pascual-Pasto G, Bazan-Peregrino M, N G O, et al. Therapeutic targeting of the RB1 pathway in retinoblastoma with the oncolytic adenovirus VCN-01. Sci Transl Med. 2019;11(476):eaat9321. doi:10.1126/scitranslmed.aat9321

10. Zhang J, Benavente CA, McEvoy J, et al. A novel retinoblastoma therapy from genomic and epigenetic analyses. Nature. 2012;481 (7381):329-334. doi:10.1038/nature10733

11. Plousiou M, Vannini I. Non-coding RNAs in retinoblastoma. Front Genet. 2019;10:1155. doi:10.3389/fgene.2019.01155

12. Khorkova O, Hsiao J, Wahlestedt C. Basic biology and therapeutic implications of lncRNA. Adv Drug Deliv Rev. 2015;87:15-24. doi:10.1016/j.addr.2015.05.012

13. Hu L, Chen SH, Lv QL, et al. Clinical significance of long non-coding RNA CASC8 rs10505477 polymorphism in lung cancer susceptibility, platinum-based chemotherapy response, and toxicity. Int J Environ Res Public Health. 2016;13(6):545. doi:10.3390/ijerph13060545
14. Slabáková E, Culig Z, Remšík J, et al. Alternative mechanisms of miR-34a regulation in cancer. Cell Death Dis. 2017;8(10):e3100e3100. doi:10.1038/cddis.2017.495

15. Cui Z, Gao M, Yin Z, et al. Association between lncRNA CASC8 polymorphisms and the risk of cancer: a meta-analysis. Cancer Manag Res. 2018;10:3141-3148. doi:10.2147/CMAR.S170783

16. Yao K, Hua L, Wei L, et al. Correlation between CASC8, SMAD7 polymorphisms and the susceptibility to colorectal cancer: an updated meta-analysis based on GWAS results. Medicine (Baltimore). 2015;94(46):e1884. doi:10.1097/MD.0000000000001884

17. Wu ER, Hsieh MJ, Chiang WL, et al. Association of IncRNA CCAT2 and CASC8 gene polymorphisms with hepatocellular carcinoma. Int J Environ Res Public Health. 2019;16(16):2833. doi:10.3390/ijerph16162833

18. Hashemi M, Bahari G, Naderi M, et al. Association of lnc-LAMC2-1: 1 rs2147578 and CASC8 rs10505477 polymorphisms with risk of childhood acute lymphoblastic leukemia. Asian Pac J Cancer Prev. 2016;17(11):4985-4989.

19. Yang G, Fu Y, Lu X, et al. miR-34a regulates the chemosensitivity of retinoblastoma cells via modulation of MAGE-A/p53 signaling. Int J Oncol. 2019;54(1):177-187.

20. Su Y, Lu S, Li J, et al. Shikonin-mediated up-regulation of miR-34a and miR-202 inhibits retinoblastoma proliferation. Toxicol Res (Camb). 2018;7(5):907-912. doi:10.1039/C8TX00079D

21. Liu C, Kelnar K, Liu B, et al. The microRNA miR-34a inhibits prostate cancer stem cells and metastasis by directly repressing CD44. Nat Med. 2011;17(2):211-215. doi:10.1038/nm.2284

22. Li N, Fu H, Tie Y, et al. miR-34a inhibits migration and invasion by down-regulation of c-Met expression in human hepatocellular carcinoma cells. Cancer Lett. 2009;275(1):44-53. doi:10.1016/j.canlet.2008.09.035
Cancer Management and Research

\section{Publish your work in this journal}

Cancer Management and Research is an international, peer-reviewed open access journal focusing on cancer research and the optimal use of preventative and integrated treatment interventions to achieve improved outcomes, enhanced survival and quality of life for the cancer patient.

\section{Dovepress}

The manuscript management system is completely online and includes a very quick and fair peer-review system, which is all easy to use. Visit http://www.dovepress.com/testimonials.php to read real quotes from published authors. 